\title{
CFD AND THERMAL ANAYSIS ON AC CONDENSOR
}

\author{
Mr. B. Phanindra Kumar (Assistant professor) \\ Dheeravath. Prasad Naik Kuntla. Pranadeep Reddy Gollagadda. Madhusudhan Goud \\ , Department of Mechanical Engineering \\ Guru Nanak Institute of Technology, Hyderabad.
}

\section{ABSTRACT}

In systems involving heat transfer, a condenser is a device or unit used to condense a substance from its gaseous to its liquid state, by cooling it. In so doing, the latent heat is given up by the substance, and will transfer to the condenser coolant. Condensers are typically heat exchangers which have various designs and come in many sizes ranging from rather small (hand-held) to very large industrial-scale units used in plant processes. For example, a refrigerator uses a condenser to get rid of heat extracted from the interior of the unit to the outside air. Condensers are used in air conditioning, industrial chemical processes such as distillation, steam power plants and other heat-exchange systems. Use of cooling water or surrounding air as the coolant is common in many condensers.
In general all solid and non solid model will deform when certain amount of thermal or structural loads applied within the environmental condition. In order to find the changes of the product or component, a analysis software is used. Ansys is an analytic software to find changes in deformation, Product life, Failures, heat flux(change of heat flow with respect to time and distance) and CFD (flow of air or water or any gas or liquid in the body).

In this project the model is Designed with respect to all the available constraints using an advanced cad softwares like Creo parametric, solid works, catia and solid edge. Later the product file is converted to ".stp" file format (standard exchange of product file) and imported to ansys workbench to find deformation and analytic valve with respect to the model or product definitions.

In this project the product was undergone various types of analysis to find frequencies with respect to gravity or mass by using Modal analysis and by Using static structural analysis total deformation, stress and strain valve, product life 
and failures etc., can be calculate by using Ansys workbench.

\section{KEY WORDS: Deformation, Structural analysis}

\section{INTRODUCTION OF AC CONDENSER}

\subsection{Condenser}

The condenser coil of an AC. In systems involving heat transfer, a condenser is a device or unit used to condense a substance from its gaseous to its liquid state, by cooling it. In so doing, the latent heat is given up by the substance, and will transfer to the condenser coolant. Condensers are typically heat which have various designs and come in many sizes ranging from rather small (hand-held) to very large industrial-scale units used in plant processes. For example, a refrigerator uses a condenser to get rid of heat extracted from the interior of the unit to the outside air. Condensers are used in air conditioning, industrial chemical processes such as distillation, steam power plants and other heat-exchange systems. Use of cooling water or surrounding air as the coolant is common in many condensers.

\subsection{Examples Of Condensers}

Surface condenser is an example of such a heat-exchange system. It is a shell and tube heat exchanger installed at the outlet of every steam turbine in thermal power stations. Commonly, the cooling water flows through the tube side and the steam enters the shell side where the condensation occurs on the outside of the heat transfer tubes. The condensate drips down and collects at the bottom, often in a built-in pan called a hotel. The shell side often operates at a vacuum or partial vacuum, often produced by attached air ejectors. Conversely, the vapor can be fed through the tubes with the coolant water or air flowing around the outside.

In chemistry, a condenser is the apparatus which cools hot vapors, causing them to condense into a liquid. See "Condenser (laboratory)" for laboratory-scale condensers, as opposed to industrial-scale condensers. Examples include the Liebig condenser, Graham condenser, and Allihn condenser. This is not to be confused with a condensation reaction which links two fragments into a single molecule by an addition reaction and an elimination reaction. In laboratory distillation, reflux, and rotary evaporators, several types of condensers are commonly used. The Liebig condenser is simply a straight tube within a cooling water jacket, and is the simplest (and relatively least expensive) form of condenser. The Graham condenser is a spiral tube within a water jacket, and the Allihn condenser has a series of large and small constrictions on the inside tube, each increasing the surface area upon which the vapor constituents may condense. Being more complex shapes to manufacture, these latter types are also more expensive to purchase. These three types of condensers are laboratory 
glassware items since they are typically made of glass. Commercially available condensers usually are fitted with ground glass joints and come in standard lengths of 100, 200, and $400 \mathrm{~mm}$. Aircooled condensers are unjacketed, while watercooled condensers contain a jacket for the water.

Larger condensers are also used in industrial-scale distillation processes to cool distilled vapor into liquid distillate. Commonly, the coolant flows through the tube side and distilled vapor through the shell side with distillate collecting at or flowing out the bottom.

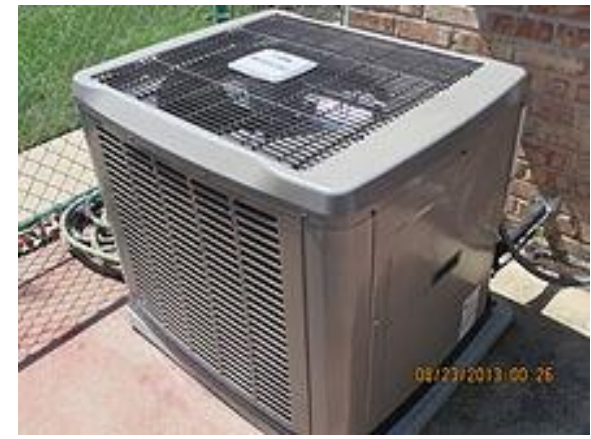

Figure 1. 1 Condenser Unit For Central Air Conditioning For A Typical House

A condenser unit used in central air conditioning systems typically has a heat exchanger section to cool down and condense incoming refrigerant vapor into liquid, a compressor to raise the pressure of the refrigerant and move it along, and a fan for blowing outside air through the heat exchanger section to cool the refrigerant inside. A typical configuration of such a condenser unit is as follows: The heat exchanger section wraps around the sides of the unit with the compressor inside. In this heat exchanger section, the refrigerant goes through multiple tube passes, which are surrounded by heat transfer fins through which cooling air can move from outside to inside the unit. There is a motorized fan inside the condenser unit near the top, which is covered by some grating to keep any objects from accidentally falling inside on the fan. The fan is used to blow the outside cooling air in through the heat exchange section at the sides and out the top through the grating. These condenser units are located on the outside of the building they are trying to cool, with tubing between the unit and building, one for vapor refrigerant entering and another for liquid refrigerant leaving the unit. Of course, an electric power supply is needed for the compressor and fan inside the unit.

\subsection{Direct Contact Condenser}

In this type of condenser, vapors are poured into the liquid directly. The vapors lose their latent heat of vaporization; hence, vapors transfer their heat into liquid and the liquid becomes hot. In this type of condensation, the vapor and liquid are of same type of substance. In another type of direct contact condenser, cold water is sprayed into the vapor to be condensed.

\subsection{Other Types Of Condensers}

In the world of Heating, Ventilation, and Air Conditioning (HVAC), condensers happen to be a topic of great importance. Instead of confusing 
information, the goal is to provide some basic information on the different types of condensers and their applications.

There are three other condensers used in HVAC systems

- Water-cooled

- Air-cooled

- Evaporative

\section{LITERATURE REVIEW}

Air cooled - If the condenser is located on the outside of the unit, the air cooled condenser can provide the easiest arrangement. These types of condensers eject heat to the outdoors and are simple to install.

Most common uses for this condenser are domestic refrigerators, upright freezers and in residential packaged air conditioning units. A great feature of the air cooled condenser is they are very easy to clean. Since dirt can cause serious issues with the condensers performance, it is highly recommended that these be kept clear of dirt.

Water cooled - Although a little more pricey to install, these condensers are the more efficient type. Commonly used for swimming pools and condensers piped for city water flow, these condensers require regular service and maintenance.

They also require a cooling tower to conserve water. To prevent corrosion and the forming of algae, water cooled condensers require a constant supply of makeup water along with water treatment.

Depending on the application you can choose from tube in tube, shell and coil or shell and tube condensers. All are essentially made to produce the same outcome, but each in a different way.

Evaporative - While these remain the least popular choice, evaporative condensers can be used inside or outside of a building and under typical conditions, operate at a low condensing temperature.

Typically these are used in large commercial airconditioning units. Although effective, they are not necessarily the most efficient.

Prior to beginning your install, make sure you choose a condenser that will provide you with the most efficient use.

\section{Equation}

For an ideal single-pass condenser whose coolant has constant density, constant heat capacity, and linear enthalpy over the temperature range, perfect cross-sectional heat transfer, and zero longitudinal heat transfer, and whose tubing has constant perimeter, constant thickness, and constant heat conductivity, and whose condensable fluid is perfectly mixed and at constant temperature, the coolant temperature varies along its tube according to:

Where:

$\mathrm{x}$ is the distance from the coolant inlet; 
$\mathrm{T}(\mathrm{x})$ is the coolant temperature, and $\mathrm{T}(0)$ the coolant temperature at its inlet;

$\mathrm{T}_{\mathrm{H}}$ is the hot fluid's temperature;

NTU is the number of transfer units;

$\mathrm{m}$ is the coolant's mass (or other) flow rate;

$\mathrm{c}$ is the coolant's heat capacity at constant

pressure per unit mass (or other);

$\mathrm{h}$ is the heat transfer coefficient of the coolant tube;

$\mathrm{P}$ is the perimeter of the coolant tube;

$\mathrm{G}$ is the heat conductance of the coolant tube (often denoted UA);

$\mathrm{L}$ is the length of the coolant tube.

Wang et al. (1999) conducted an experimental study on the air-side performance for two specific louver fin patterns and their plain plate fin counterparts. This study investigated the effects of fin pitch, longitudinal tube spacing and tube diameter on the air-side heat transfer performance and friction characteristics. This study found that for plain plate fin configurations ranging from 8 to 14 fins per inch, the effect of longitudinal tube pitch on the air-side was negligible for both the airside heat transfer and pressure drop. However, the heat transfer performance increased with reduced fin pitch [1].

\section{METHODOLOGY}

\subsection{Methodology}

$>$ Create a 3D model of the ac condenser assembly using

parametric software pro-engineer.

$>$ Convert the surface model into Para solid file and import the model into ANSYS to do analysis.

$>$ Perform thermal analysis on the ac condenser assembly for thermal loads.

> Perform CFD analysis on the existing model of the surface ac condenser for Velocity inlet to find out the mass flow rate, heat transfer rate, pressure drop.

\subsection{OBJECTIVE}

The objective of this project is to make a 3D model of theac condenser and study the CFD and thermal behavior of theac condenser by performing the finite element analysis.3Dmodeling software (PRO-Engineer) was used for designingand analysis software (ANSYS) was used for CFD and thermal analysis.

\subsection{DESIGN AND MODELLING OF ENVIRONMENT TEST CHAMBER}

PRO/ENGINEER offers a solution to shape water cooled condensers. In the present design, styling, surfacing workflow and work, the performance analysis of air cooled visualization to create, modify, and validate condensing unit has been carried out by complex innovative shapes from 
industrial varying the fin material and fin thickness. At design to Class-A surfacing with the ICEM present aluminum alloy 204 is being used surfacing technologies. PRO/ENGINEER for fins. supports multiple stages of product design Two fin materials namely, Aluminumallop whether started from scratch or from 2D

1100 and 1050were considered to study the sketches. PRO/ENGINEER is able to read effect of fin's thermal conductivity on the and produce STEP format files for reverse performance of the condenser. Pro Engineer engineering and surface reuse is used to model the system. For thermal analysis purpose ANSYS Works software is used. Considering different factors for a condenser, such as heat transfer, density etc., and Aluminum alloy 1100 is found to be the best fin material.

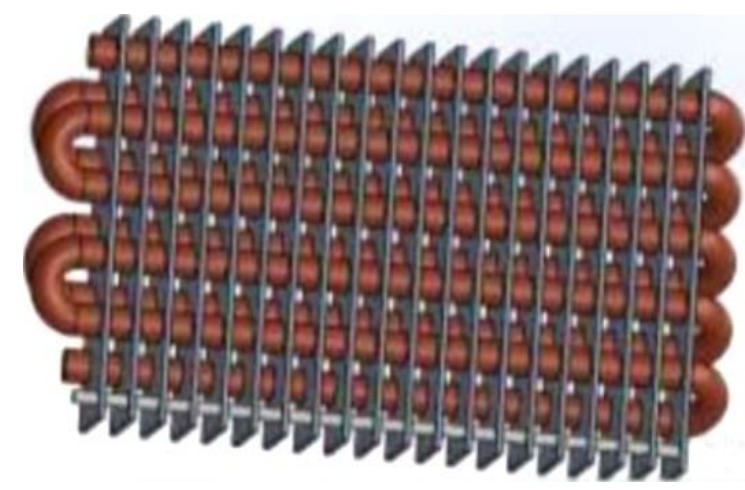

Figure 2.1: Sketcher of condenser coil

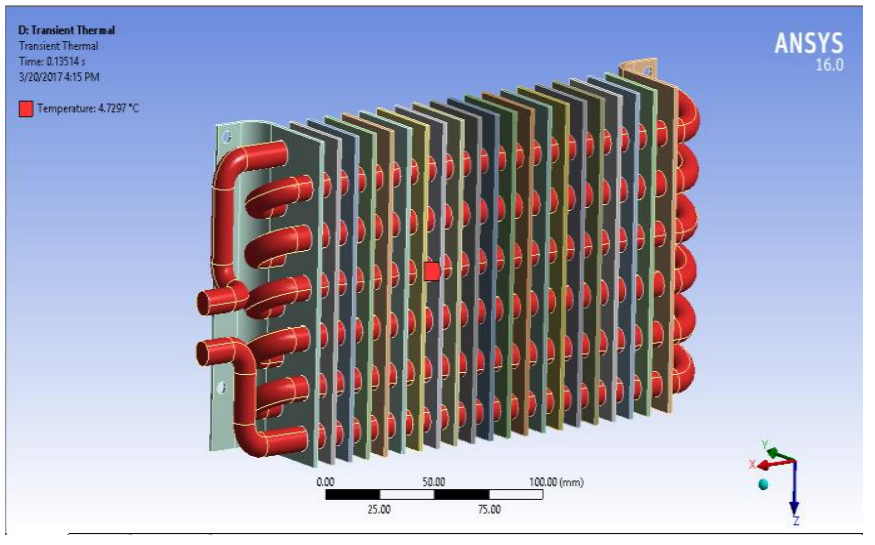

Figure 2.2The Details Of "Temperature" \& The Color Contours Displayed Window In The Graphics Screen

\section{CONCLUSION}

In this project modeling and analysis of ac condenser is carried out. The ac condenser is modeled with the help of solid works software and the component is meshed and analysis is done in ANSYS software and the thermal behavior is studied and the results are tabulated. The various materials acting on the ac condenser under various actual temperature conditions have been studied.

The ac condenser of an air condition is usually built up from an inner and an outer atmospherically temperature surrounding the inner chamber to foam an intermediate or annular space. Particularly after the condenser has been shut down, temperature difference appear on the room and between surrounding can be differences can be more than 50 Kelvin's The designing of component 
is done in solid works part design and assembly of different component is done assembling designing

1. Then the assembly of components file is saved in the format of STP or IGES file.

2. Then the STP or IGES file is imported into Ansys workbench

3. With the help of Transient thermal analysis the results are measure

4. By using material for body with respect to table, the temperature around the ac conductor was measured.

\section{ACKNOWLEDGEMENT}

The mini project entitled "CFD AND THERMAL ANAYSIS ON AC CONDENSOR" is the sum of total efforts of our batch. It is our duty to bring forward each and every one who is directly or indirectly in relation with our project and without who it would not have gained a structure.

We wish to convey our sincere thanks to our internal guide Mr.B.PHANIDRA, Assistant professor in Mechanical Engineering, for his profession encouragement in starting this project and academic guidance during the course this project.

We wish to convey our sincere thanks to Dr. B. VIJAYA KUMAR, Head of the Department, Mechanical Engineering, for his professional advice,encouragement in starting this project and academic guidance during the course of this project.
We wish to express our candid gratitude to Principal Dr. S. SREENATHA REDDY and management of Guru Nanak Institute of Technology for providing the required facilities to complete our project successfully.

We are also grateful to our well-wishers and friends, whose co-operation and some suggestions have helped us in completing the project.

Finally, we would like to thank our parents for their exemplary tolerance and giving us enough support in our endeavors.

\section{REFERENCE}

[1] Wang, C. C., Lee, C. J., Chang, C. T., and Chang Y. J., 1999. "Some Aspects of Plate FinandTube Heat Exchangers with and without Louvers," J. Enhanced Heat Transfer, vol. 6, no. 5, pp. 357368.

[2] Wang, C. C., Chi, Y. P. Chang, K. Y. C., and Chang, Y. J., 1998. "An Experimental Study of Heat Transfer and Friction Characteristics of Typical Louver Fin and Tube Heat Exchangers," Int. J. of Heat and Mass Transfer, vol. 41, no. 4-5, pp.817-822.

[3] Chi, K., Wang, C. C., Chang, Y. J., and Chang, Y. P., 1998. "A Comparison Study of Compact Plate Fin-and-Tube Heat Exchangers," ASHRAE Transactions, vol. 104, no. 2, pp. 548-555. 
[4]. Kays, W. M. and London, A. L., 1984.

Compact Heat Exchangers, 3rd Edition, McGrawHill, New York.

[5]. Shepherd, D. G., 1956. "Performance of OneRow Tube Coils with Thin Plate Fins," Heating, Piping, \& Air Conditioning, vol. 28, no. 4, pp. 137- 144

[6]. Rich, D. G., 1973. "The Effect of Fin Spacing on the Heat Transfer and Friction Performance of Multi-Row, Smooth Plate Fin-and-Tube Heat
International Journal of Engineering Research \& Technology (IJERT) Vol. 2 Issue 1, January- 2013 ISSN: 2278-0181 www.ijert.org 10 IJERT Exchangers,"ASHRAE Transactions, vol. 79, pt. 2, pp. 137-145.

[7] 2001 ASHRAE Handbook of Fundamentals

[8] 1997 ASHRAE Handbook of Fundamentals 